Proceedings of XIX International Scientific Conference "New Technologies and Achievements in Metallurgy, Material Engineering, Production Engineering and Physics", Częstochowa, Poland, June 7-8, 2018

\title{
The Influence of Structure Defects on Magnetization Process of Bulk Amorphous $\mathrm{Fe}_{63} \mathrm{Co}_{8} \mathrm{Y}_{8} \mathrm{~W}_{1} \mathrm{~B}_{20}$ Alloy
}

\author{
M. NABialeK, K. Jez And B. JeZ* \\ Institute of Physics, Częstochowa University of Technology, al. Armii Krajowej 19, 42-200 Częstochowa, Poland
}

\begin{abstract}
The paper presents the results of investigations of the structure and magnetic properties of bulk high-melt $\mathrm{Fe}_{63} \mathrm{Co}_{8} \mathrm{Y}_{8} \mathrm{~W}_{1} \mathrm{~B}_{20}$ alloy in the form of $0.5 \mathrm{~mm}$ thick plates manufactured using the method of pressing liquid alloy into the copper mold. The structure of the obtained samples was examined using an X-ray diffractometer and magnetic properties using a vibration magnetometer. All tested samples in the as cast state had an amorphous structure. Analysis of the curves of primary magnetization based on the theory of Kronmüller that indirectly examined the structure was made. Their type was determined. The stiffness parameter of the spin wave was also determined, which is directly related to the magnetization of the sample in the area affected by the damping of spin waves.
\end{abstract}

DOI: 10.12693/APhysPolA.135.136

PACS/topics: 75.50.--y, 75.50.Kj, 75.50.Bb, 75.60.Ej, 75.47.Np, 75.30.Ds

\section{Introduction}

Amorphous materials have been the object of research of scientists for several decades. Despite many years of research, the amorphous structure and its corresponding properties have still not been fully described and explained. It is the reason why these materials are still very popular among many scientific centers. Alloys having an amorphous structure are characterized by different properties than their crystalline counterparts with the same chemical composition [1]. Particularly interesting in the group of amorphous alloys are ferromagnetic materials and in particular with soft magnetic properties. They show a low value of coercivity field and core losses and relatively high magnetization of saturation. Such alloys are also called almost zero magnetostrictive materials. Therefore, they can be used in power engineering and in the electrotechnical industry [2].

Generally, amorphous alloys were produced in the form of thin layers and tapes, whose thickness did not exceed $100 \mu \mathrm{m}$ which significantly limits the applicability of this type of materials [3]. Therefore, intensive work was carried out on alloys with larger thicknesses. As a result of these works, a new group of materials was created, the so-called massive amorphous materials. The greatest contribution to this group of materials was made by Inoue from the University of Tohaku who proposed three principles for their production. He assumed that the multicomposed nature of the alloy, the negative heat of mixing and the correspondingly large differences in the length of the atomic rays of the main alloy components give a good chance of obtaining the amorphous structure of the material $[4,5]$.

*corresponding author; e-mail: bartek199.91@o2.pl
Massive amorphous materials are produced, among others, in the process of injecting or sucking a liquid alloy into a copper mold. The required cooling rate for massive amorphous materials is much lower than for classical ones in the form of tapes $\left(10^{-1}-10^{3} \mathrm{~K} / \mathrm{s}\right)$.

The unique magnetic properties of amorphous alloys are directly related to the unusual structure of these materials. One of the methods of studying the real structure of amorphous materials is the analysis of the curves of the primary magnetization in accordance with the theory of Kronmüller, or the so-called approach to ferromagnetic saturation area $[6,7]$. Using this theory, one can determine the amount and type of structural defects found in amorphous alloys. As a result of the rapid cooling of the liquid melt, disruption of the structure in the form of near and intermediate stresses is created in its volume. The resulting stresses take on the form of free volumes and pseudodislocation dipoles [8]. The number and type of these defects have a significant impact on the process of magnetizing the amorphous material in the area of approach to ferromagnetic saturation.

Guided by the criteria of Inoue, the chemical composition of $\mathrm{Fe}_{63} \mathrm{Co}_{8} \mathrm{Y}_{8} \mathrm{~W}_{1} \mathrm{~B}_{2}$ alloy was established. The work presents structure tests of the obtained alloy. The aim of the study was to indirectly determine the type of structural defects and to determine the spin wave stiffness parameter $\left(D_{\mathrm{sp}}\right)$.

\section{Materials and methods}

The first stage in the production of amorphous materials was the weighing of alloy components with an accuracy of $0.001 \mathrm{~g}$. Samples were prepared from high $99.99 \%$ purity. Using the arc furnace, the alloy components were solidified. The process of combining the elements took place in a protective atmosphere of argon after earlier production of a high vacuum in the furnace working chamber. The polycrystalline ingot was melted 
several times in order to obtain homogeneity of the chemical composition in its volume. Amorphous alloys were created by means of injection casting and suction of a liquid alloy into a copper mold. The batch melting process was carried out in a protective argon atmosphere by means of eddy currents. The alloy was solidified in the form of $10 \mathrm{~mm} \times 5 \mathrm{~mm} \times 0.5 \mathrm{~mm}$ tiles. The structure of the produced materials was examined with a Brucker Xray diffractometer equipped with a $\mathrm{Cu} K_{\alpha}$ lamp. The study was conducted for an angle range of two theta $30^{\circ}$ to $100^{\circ}$ for powdered samples.

Magnetic testing of the produced alloy was carried out using a Lake Shore vibration magnetometer. The curve of the primary magnetization was measured in the magnetic field up to $1.7 \mathrm{~T}$.

According to Kronmüller's theory, magnetization near the area known as the approach to ferromagnetic saturation can be defined as:

$$
\begin{aligned}
& \mu_{0} M(H)=\mu_{0} M_{s}\left[1-\frac{a_{1 / 2}}{\left(\mu_{0} H\right)^{1 / 2}}-\frac{a_{1}}{\left(\mu_{0} H\right)^{1}}-\frac{a_{2}}{\left(\mu_{0} H\right)^{2}}\right] \\
& \quad+b\left(\mu_{0} H\right)^{1 / 2}
\end{aligned}
$$

where $M_{s}$ - spontaneous magnetization, $\mu_{0}$ - magnetic permeability of vacuum, $H-$ magnetic field, $a_{i}\left(i=\frac{1}{2}\right.$, $1,2)$ - angular coefficients of the linear fit, which correspond to the free volume and linear defects, $b$ - slope of the linear fit corresponding to the thermally induced suppression of spin waves by a magnetic field of high intensity.

\section{Research}

Figure 1 presents measured X-ray diffractograms for the alloys produced. In registered images (Fig. 1a,b) only the broad maximum from the distorted phase is visible. Such X-ray diffraction patterns are typical for amorphous materials. Figure 2 presents the curves of primary magnetization for the tested samples on which the area of the so-called ferromagnetic saturation approach was determined. This area is above the effective anisotropy field where the magnetization process corresponds to the previously described defects of the amorphous structure and ends when the magnetization process is related to the Holstein-Primakoff paraprocess [9].

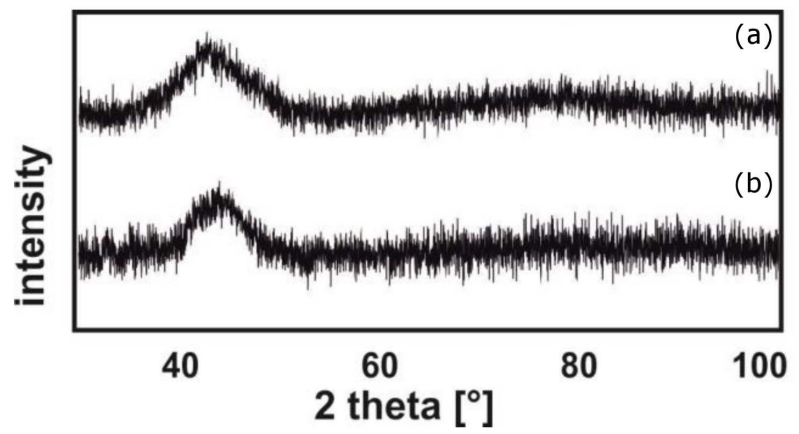

Fig. 1. XRD diffractograms for $\mathrm{Fe}_{63} \mathrm{Co}_{8} \mathrm{Y}_{8} \mathrm{~W}_{1} \mathrm{~B}_{20}$ in the as-quenched state (ASQ) made by: (a) injection, (b) suction casting.

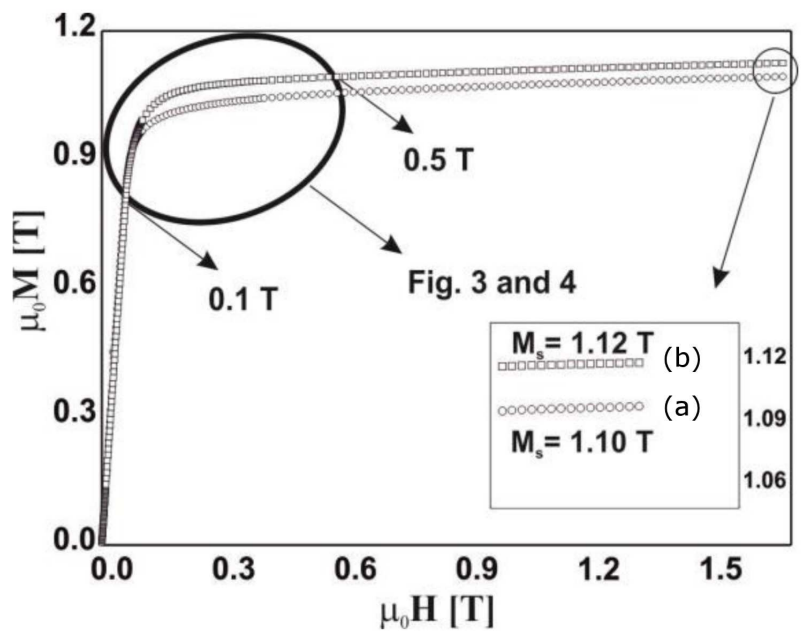

Fig. 2. Primary magnetization curves for $\mathrm{Fe}_{63} \mathrm{Co}_{8} \mathrm{Y}_{8} \mathrm{~W}_{1} \mathrm{~B}_{20}$ in the form of plate made by: (a) injection, (b) suction casting.

The produced samples of the alloy were characterized by the similar saturation magnetization value $(1.1 \mathrm{~T}$ for injection and $1.12 \mathrm{~T}$ for suction casting) and a similar coercive field value $(\approx 230 \mathrm{~A} / \mathrm{m})$. According to the theory of Kronmüller, adjustments were made to linear relationships for the course of the original magnetization curve in the area of approach to ferromagnetic saturation.
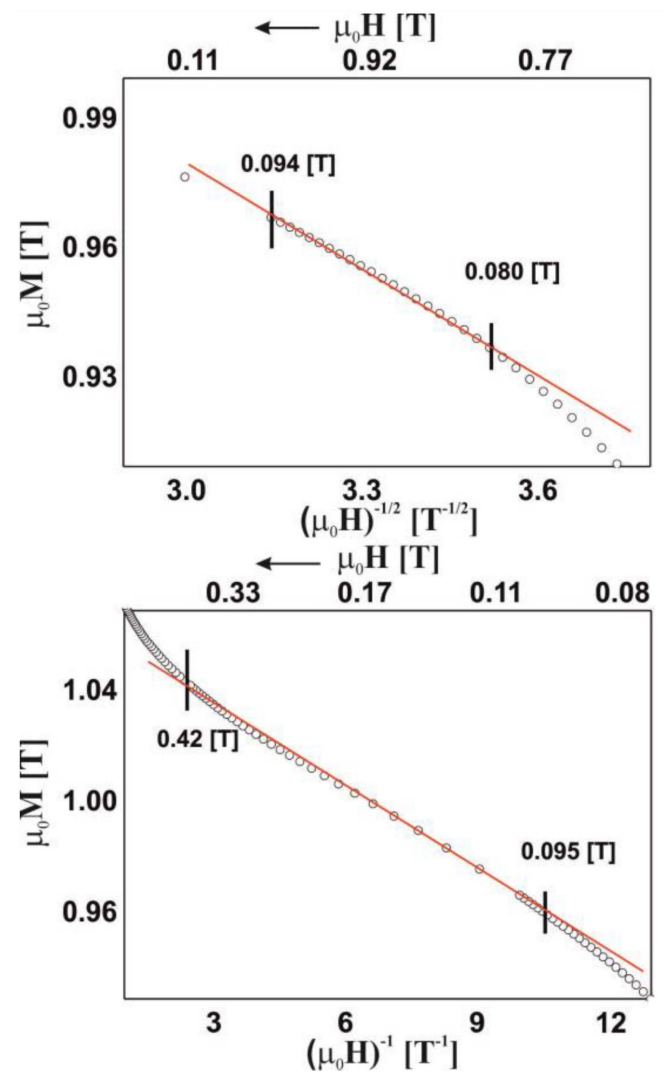

Fig. 3. High-field magnetic polarization curves as a function of $\left(\mu_{0} H\right)^{-1 / 2}$ and $\left(\mu_{0} H\right)^{-1}$ for $\mathrm{Fe}_{63} \mathrm{Co}_{8} \mathrm{Y}_{8} \mathrm{~W}_{1} \mathrm{~B}_{20}$ alloy made by injection. 


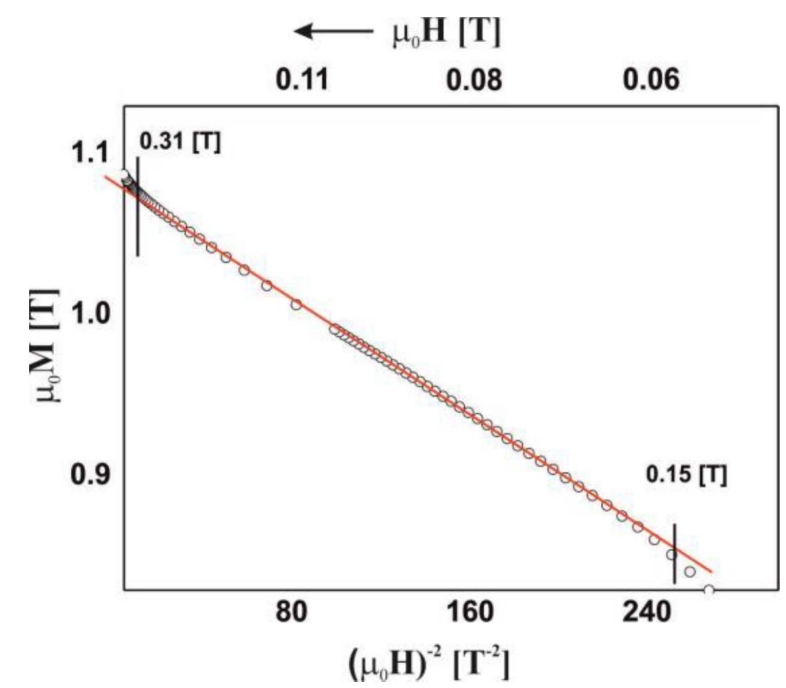

Fig. 4. High-field magnetic polarization curves as a function of $\left(\mu_{0} H\right)^{-2}$ for $\mathrm{Fe}_{63} \mathrm{Co}_{8} \mathrm{Y}_{8} \mathrm{~W}_{1} \mathrm{~B}_{20}$ alloy made by suction casting.

Figure 3 shows the linear fit according to $\left(\mu_{0} H\right)^{-1 / 2}$ and $\left(\mu_{0} H\right)^{-1}$ alloy $\mathrm{Fe}_{63} \mathrm{Co}_{8} \mathrm{Y}_{8} \mathrm{~W}_{1} \mathrm{~B}_{2}$ prepared by injection casting. In the case of this sample, the magnetization process in strong magnetic fields is related to the rotation of the magnetization vector near point defects and pseudo-location dipoles. On the other hand, for the suction sample, the dominant role in the magnetization process in the area of the approach to ferromagnetic saturation has inhomogeneities in the structure in the form of pseudo-dislocation dipoles (Fig. 4).

Figure 5 presents curves describing the dependence $\mu_{0} M\left(\mu_{0} H\right)^{1 / 2}$ for $\mathrm{Fe}_{63} \mathrm{Co}_{8} \mathrm{Y}_{8} \mathrm{~W}_{1} \mathrm{~B}_{20}$ in the area above the approach to ferromagnetic saturation.

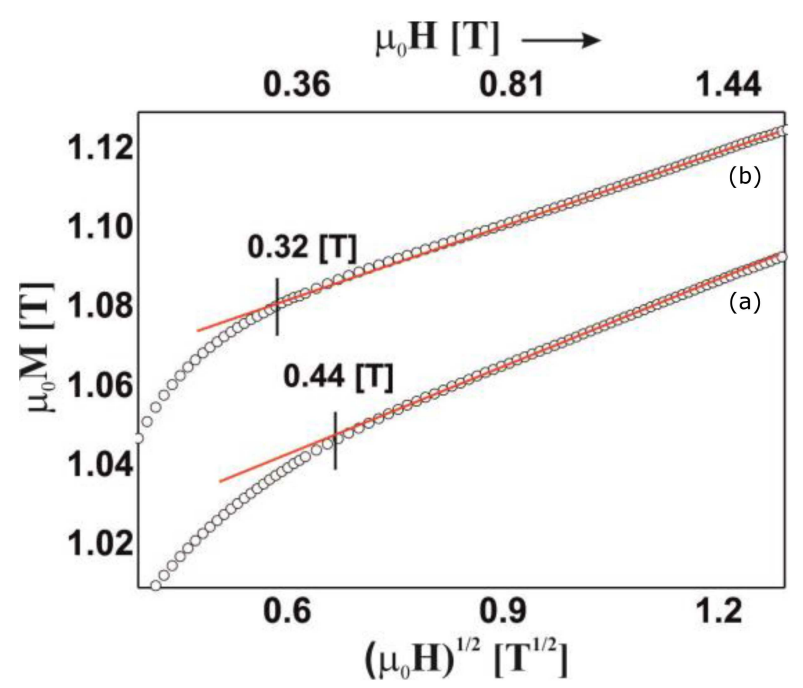

Fig. 5. High-field magnetic polarization curves as a function of $\left(\mu_{0} H\right)^{1 / 2}$ for $\mathrm{Fe}_{63} \mathrm{Co}_{8} \mathrm{Y}_{8} \mathrm{~W}_{1} \mathrm{~B}_{20}$ alloy made by: (a) injection, (b) suction casting.
In strong magnetic fields above the anisotropy field, where the magnetizing process is not related to the stresses of the near and middle range structure, the dominant role in its course have thermally suppressed spin waves. Using the relationship (2) [10], the parameter $D_{\text {sp }}$ was calculated

$$
b=3.54 g \mu_{0} \mu_{\mathrm{B}}\left(\frac{1}{4 \pi D_{\mathrm{spf}}}\right)^{3 / 2} k T\left(g \mu_{\mathrm{B}}\right)^{1 / 2},
$$

which for the sample obtained by the injection method is $37.04 \mathrm{meV} \mathrm{nm}^{2}$ and the suction method $42.42 \mathrm{meV} \mathrm{nm}^{2}$.

\section{Conclusions}

Using both production methods, one can obtain samples with an amorphous structure from the alloy $\mathrm{Fe}_{63} \mathrm{Co}_{8} \mathrm{Y}_{8} \mathrm{~W}_{1} \mathrm{~B}_{20}$. In general, the method of introducing a liquid alloy into a mold has no effect on the coercive field value, which is approximately $230 \mathrm{~A} / \mathrm{m}$ for both alloys. However, the difference in the saturation of the sample can be seen depending on the method of its production. The $D_{\text {sp }}$ parameter is related to the magnetic environment by other magnetic atoms, in our case $\mathrm{Fe}-\mathrm{Fe}$, $\mathrm{Fe}-\mathrm{Co}, \mathrm{Co}-\mathrm{Co}$. It should be assumed that a higher value of saturation is associated with a higher value of the $D_{\mathrm{sp}}$ parameter as indicated by the results. However, it happens that for a higher value of parameter $D_{\mathrm{sp}}$, a lower saturation value is obtained [11]. This fact is related to too close distances between magnetic atoms, which makes antiferromagnetic order more beneficial in terms of energy. Based on the observation of the so-called the approach to ferromagnetic saturation was found that the rotations of the magnetization vector are related to the heterogeneities of the magnetic structure.

\section{References}

[1] A. Inoue, N. Yano, T. Masumoto, J. Mater. Sci. 19, 3786 (1984).

[2] M.E. McHenry, M.A. Willard, D.E. Laughlin, Prog. Mater. Sci. 44, 291 (1999).

[3] A. Inoue, T. Zhang, T. Masumoto, Mater. Trans. JIM 31, 177 (1990).

[4] A. Inoue, A. Kato, T. Zhang, S.G. Kim, T. Masumoto, Mater. Trans. JIM 32, 609 (1991).

[5] M. Nabiałek, Arch. Metall. Mater. 61, 439 (2016).

[6] H. Kronmüller, M. Fahnle, H. Grimm, R. Grimm, B. Groger, J. Magn. Magn. Mater. 13, 53 (1979).

[7] H. Kronmüller, IEEE Trans. Magn. 15, 1218 (1979).

[8] K. Bloch, M. Nabialek, Acta Phys. Pol. A 127, 413 (2015).

[9] H. Kronmüller, S. Parkin, Handbook of Magnetism and Advanced Magnetic Materials, Vol. 2, Wiley, Hoboken 2007.

[10] M. Nabialek, Arch. Metall. Mater. 60, 1987 (2015).

[11] M. Nabialek, J. Alloys Comp. 645, 98 (2015). 